\title{
Involvement of Merkel cell polyomavirus in the etiology and pathogenesis of Merkel cell carcinoma: A systematic review
}

\author{
Fernando Seiji Morais, Caio Santos Bonilha, Emerson Carraro \\ Pharmacy Department, Masters Program in Pharmaceutical Sciences, Universidade Estadual do Centro-Oeste (State University of Center-West) \\ (UNICENTRO), Guarapuava-PR, Brazil
}

Email address:

fernandoseiji.morais@yahoo.com.br (F. S. Morais), caiosantosb@hotmail.com (C. S. Bonilha), emersoncarraro@bol.com.br (E. Carraro)

To cite this article:

Fernando Seiji Morais, Caio Santos Bonilha, Emerson Carraro. Involvement of Merkel Cell Polyomavirus in the Etiology and Pathogenesis of Merkel Cell Carcinoma: A Systematic Review. Cancer Research Journal. Special Issue: Lifestyle and Cancer Risk.

Vol. 2, No. 6-1, 2014, pp. 1-10. doi: 10.11648/j.crj.s.2014020601.11

\begin{abstract}
Merkel Cell Polyomavirus (MCV) is a virus belonging to the human Polyomavirus family. After its discovery and detection in approximately $80 \%$ of Merkel Cell Carcinoma (MCC) tumors, it has been associated with this rare and aggressive skin cancer that primarily affects elderly and immunosuppressed people. In this study, a systematic review was developed to gather and evidence information about the involvement of MCV infection in the development of MCC. An analysis was performed in the PubMed database in order to find articles to answer the purpose of this present study. Ninety-seven articles met the criteria, forty-six of them investigated the prevalence of MCV in MCC clinical samples, and all showed that the MCV-MCC association exists, with the viral presence ranging from 18 to $100 \%$ in MCC tumors. In addition, results pointing to the MCV potential carcinogenic, infection, transmission and replication mechanisms, or even possible disease markers or therapeutic evaluations were found. Current literature has demonstrated frequent involvement of MCV in MCC, with survey of some disease indicative laboratory markers and possible therapeutic evaluations.
\end{abstract}

Keywords: Merkel Cell Carcinoma, Merkel Cell Polyomavirus, Carcinogenesis

\section{Introduction}

The transformation process of normal cells into malignant tumor cells is caused by sequence genetic mutations and consists of sequential stages in cascade [1]. The genome sequencing efforts have identified a large number of somatic genomic alterations and numerous germinal mutations associated with cancer predisposition. Viruses inherently depend on the host cell and during the course of infection may result in pathological phenotypes similar to those observed in mutations that lead to carcinogenesis [2].

Some associations between viruses and cancer in humans are described in the literature. Among the most common, one can cite the connection between the Epstein-Barr virus (EBV) and gastric tract cancers, Burkitt's lymphoma and nasopharyngeal carcinomas [3]; hepatitis $\mathrm{C}$ virus (HCV) and the hepatocellular carcinoma [4]; and human papillomavirus (HVP) and cervical, anal, vaginal, vulvar and penile cancers [5].

Merkel Cell Polyomavirus (MCV) belongs to the family of human Polyomaviruses. This family consists of 10 members, being so far the MCV the only associated with cancer development, specifically Merkel Cell Carcinoma (MCC) [6]. $\mathrm{MCV}$ is a small, non-enveloped and double-stranded DNA virus [7], unknown until mid-2008 when his DNA was found in tumors of MCC. Thenceforth, the MCV has been reported in approximately $80 \%$ of cases of individuals with MCC [8].

MCC is a rare type of skin cancer of neuroendocrine origin [6] and was first described in 1972 by Toker [9]. This potentially fatal cancer consists of a malignant tumor that affects mostly white elderly people and immunocompromised individuals, such as transplant or AIDS patients. Other possible risk factors for the development of this cancer are histories of non-melanoma skin cancer, leukemia or lymphoma [10, 11]. The incidence of MCC increased sharply between mid-70's and 2006, tripling over this period (from 0.2 to $0.6 / 100,000$ cases per population in the US) [12], with a mortality rate estimated of one-third of diagnosed patients [13].

Likely due to its association with MCC, MCV has gained attention in the clinical and scientific community, as it helps to understand the etiologic context of this disease [10]. In this work, a systematic review was developed to gather information and evidence about the involvement of $\mathrm{MCV}$ infection in the development of the MCC. 


\section{Methods}

A systematic review in PubMed database was performed using the keywords "Merkel cell carcinoma" and "Merkel cell polyomavirus," in search of original papers concerning the MCV-MCC association published between February 2008 and September 2014 and with available summary. The literature survey was done in the months from May to October 2014.

The studies were selected through the title, summaries and further reading of the full work. Clinical trials, case reports, in vitro assays and research and support works were analyzed. Ninety-seven studies that met the inclusion criteria for this study were selected.

\section{Results and Discussion}

\subsection{Results}

The 97 studies selected for review were analyzed. Among the studies investigating the prevalence of MCV in MCC clinical samples (46 studies), all detected the virus in at least a portion of the analyzed samples, with relatively high but variable prevalence (ranging from 18 to $100 \%$ ). And thus, confirming the MCV-MCC association. The results found in the works include the possible carcinogenic and infection mechanisms of $\mathrm{MCV}$, replication and transmission, and possible disease markers or therapeutic evaluation.

\subsection{MCV and MCC Association}

In USA, Feng and coworkers (2008) reported the presence of MCV genomic sequence in approximately $80 \%$ of MCC tissues analyzed by using the polymerase chain reaction (PCR). In addition to these findings, clonal integration of the virus into the genome of tumors was confirmed by using digital transcriptome subtraction (DTS) [14]. From this study it was suggested that MCV infection and the integration of viral DNA in the tumor cells prior to clonal expansion of tumor cells [14 - 16]. Forty-five subsequent studies conducted in various locations and using different methods for detection of MCV also showed high prevalence of MCV in MCC tumors. A few studies have reported a lower prevalence [17 19], although the integrity of the sample may have influenced the results, as well as the collection epoch, whereas samples collected at an interval of 10 years showed high divergence of positivity for MCV [17]. However, the MCV was proposed as a possible specific marker for differentiation of MCC from other histologically similar cutaneous malignancies [20 - 23]. Epidemiological studies of MCV in patients with MCC are summarized in Table 1.

With the high detection rate of $\mathrm{MCV}$ in these tumors, it was suggested that the improvement of the detection methods would increase the frequency of MCV found in MCC tumors [24 - 27]. A greater prevalence of MCV in MCC tumors using an immunohistochemical (IHC) method with Ab3 (anti-anti-idiotype antibodies), a new mouse monoclonal antibody against MCV LT (large T) antigen, compared with those obtained by the use of CM2B4, a monoclonal antibody that was traditionally used for the detection of MCV LT, were reported. Furthermore, the expansion of the MCV repertoire of primers for PCR, showed results of $100 \%$ positivity for MCV DNA in MCC samples [25, 28]. Detection of MCV with antibodies against the $\mathrm{T}$ antigens can also be used for both monitoring of therapy to assess regression, as for evaluating the stage of the disease and recurrence [29, 30]. In a prospective study, the presence of $\mathrm{T}$ antigens or neutralizing antibodies against MCV was indicated as a risk factor for development of the MCC [31].

Cytokeratin-20 (CK20) is a common marker for the identification of MCC, but despite the simultaneous presence of CK20 with seropositivity to antibodies against the MCV small T (sT) antigen was observed in MCC tumors [29], the marker should not be used to identifying viral presence in the tumor $[32,33]$. Although the MCV DNA was found in tissues from lymphoid cancers, the MCV LT antigen was not detected in tumor cells by these malignancies using monoclonal antibodies against the LT, suggesting a non-viral causation these cases [34].

The MCV DNA can be detected in healthy individuals or non-MCC patients, showing a possible contact with the virus in the general population at some stage of life, and that the infection may be asymptomatic in most individuals [35 - 37], . However, immunosuppression of the individual is the primary risk factor for cancers of viral etiology [38]. Thus, the disease state (e.g., AIDS), advanced age, or chemotherapy treatment for other malignancies can lead to a high rate of virus replication, triggering the possible carcinogenic mechanism $[11,39,40]$. When detected in MCC tissues, the viral load of $\mathrm{MCV}$ are vastly greater than those observed in non-cancerous tissues [30, 41], occurring viral mutations which appear to be specific signatures for carcinogenesis [24]. There is no apparent correlation between age or sex of individuals and the infection by MCV, however, for MCC cases, a slight tendency in females was observed [42]. Although it is most common in the skin, the MCC can metastasize [43 - 46] or become recurrent, while this makes it difficult to differentiate these two events [47].

There is a correlation between the MCC and other malignancies, especially in the skin [42], highlighting the squamous cell carcinoma (SCC) [48, 49], basal cell carcinoma (BCC) $[48,50]$, and chronic lymphocytic leukemia (CLL) [51], which lead to risk of developing MCC as a secondary cancer, and vice-versa. There are other types of cancers associated with MCC, although with less number of records, making it difficult to consolidate data [52 - 55]. Despite the association between MCC and other cancers, apparently there is no involvement of the MCV and these other malignancies [50, 53, 56 - 59]. There are a few exceptions that show association between MCC and other cancers: the presence of MCV in Kaposi's sarcoma [54] and the detection of MCV in SCC tumors, with concomitant presence of human papillomavirus (HPV) in a combined tumor of MCC and SCC, suggesting a possible synergism of oncovirus [60].

The transmission route of $\mathrm{MCV}$ is not yet established. Another study reported a mechanism of fecal-oral 
transmission as plausible after having been detected high levels of MCV in samples of digestive tract compared to samples of skin, respiratory tract, saliva and from the liver. Samples analyzed by the group for this purpose were from
non-MCC tissues [41]. Although the MCV has been detected in samples of placenta, there is no evidence of maternal-fetal transmission [61].

Table 1. Forty-six studies that show MCV-MCC association

\begin{tabular}{|c|c|c|c|}
\hline Author/year & Local of study & Method & MCV positivity \\
\hline Feng/2008 [14] & USA & PCR & $80 \%(8 / 10)$ \\
\hline Kuwamamoto/2011 [15] & Japan & PCR, IHC (CM2B4)* & $77 \%(20 / 26), 81 \%(21 / 26)$ \\
\hline Sastre-Garau/2011 [16] & France & PCR & $100 \%(10 / 10)$ \\
\hline Garneski/2011 [17] & USA, Australia & PCR & $69 \%(11 / 16), 24 \%(5 / 21)$ \\
\hline Paik/2011 [18] & Australia & IHC (CM2B4) & $18 \%(19 / 104)$ \\
\hline Duncavage/2009 [20] & USA & PCR & $78 \%(32 / 41)$ \\
\hline Erovic/2013 [23] & Canada & IHC (CM2B4) & $97 \%(29 / 30)$ \\
\hline Ota/2012 [25] & Japan & PCR, IHC (CM2B4) & $100 \%(9 / 9), 89 \%(8 / 9)$ \\
\hline Hattori/2013 [26] & Japan & PCR, IHC (CM2B4) & $88 \%(23 / 26), 77 \%(20 / 26)$ \\
\hline Carter/2009 [27] & USA & PCR, ABA (VP1a) & $77 \%(24 / 31), 94 \%(29 / 31)$ \\
\hline Rodig/2012 [28] & USA & PCR, IHC (Ab3), IHC (CM2B4) & $100 \%(60 / 60), 97 \%(56 / 58), 81 \%(46 / 57)$ \\
\hline Paulson/2010 [29] & USA & IHC (CM2B4) & $77 \%(108 / 139)$ \\
\hline Touzé/2011 [30] & France & PCR, ELISA & $75 \%(51 / 68), 65 \%(44 / 68)$ \\
\hline Faust/2013 [31] & Sweden, Norway & $\mathrm{IHC}$ & $86 \%(19 / 22), 50 \%(11 / 22)$ \\
\hline Shuda/2009 [34] & Spain & IHC (CM2B4) & $58 \%(21 / 36)$ \\
\hline Foulongne/2010 [35] & France & PCR & $78 \%(14 / 18)$ \\
\hline Wieland/2009 [36] & Germany & PCR & $88 \%(30 / 34)$ \\
\hline Loyo/2010 [41] & USA & PCR & $86 \%(6 / 7)$ \\
\hline Bhatia/2010 [43] & USA & PCR & $74 \%(17 / 23)$ \\
\hline Wetzels/2009 [45] & Netherlands & PCR & $40 \%(2 / 5)$ \\
\hline De Biase/2012 [46] & Italy & PCR & $100 \%(18 / 18)$ \\
\hline Reisinger/2010 [49] & USA & IHC (CM2B4) & $75 \%(15 / 20)$ \\
\hline Katano/2009 [54] & Japan & PCR & $55 \%(6 / 11)$ \\
\hline $\mathrm{Ly} / 2012[55]$ & Canada & IHC (CM2B4) & $63 \%(17 / 27)$ \\
\hline Busam/2009 [57] & USA & PCR, IHC (CM2B4) & $88 \%(15 / 17), 67 \%(11 / 17)$ \\
\hline Jung/2011 [58] & Korea & PCR, IHC (CM2B4) & $86 \%(12 / 14), 85 \%(11 / 13)$ \\
\hline Mangana/2010 [59] & Switzerland & PCR & $67 \%(20 / 30)$ \\
\hline Sihto/2009 [63] & Finland & PCR & $80 \%(91 / 114)$ \\
\hline Martel-Jantin/2012 [70] & France & PCR & $61 \%(59 / 97)$ \\
\hline Nakamura/2010 [71] & Japan & PCR, IHC (LT252) & $58 \%(11 / 19), 39 \%(7 / 18)$ \\
\hline Handschel/2010 [80] & Germany & PCR & $66 \%(29 / 44)$ \\
\hline Schrama/2011 [81] & Germany, Australia & PCR & $85 \%(116 / 136), 87 \%(33 / 38)$ \\
\hline Iwasaki/2013 [83] & Japan & PCR, IHC (CM2B4) & $74 \%(32 / 43), 68 \%(29 / 43)$ \\
\hline Houben/2010 [87] & USA & PCR & $78 \%(43 / 50)$ \\
\hline Hall/2012 [90] & USA & IHC (CM2B4) & $47 \%(17 / 36)$ \\
\hline Waltari/2011 [91] & Finland & PCR & $77 \%(67 / 87)$ \\
\hline Nakajima/2009 [95] & Japan & PCR & $79 \%(11 / 14)$ \\
\hline Matsushita/2014 [100] & Japan/UK & PCR, ISH, IHC (CM2B4) & $50 \%(16 / 32), 50 \%(16 / 32), 50 \%(16 / 32)$ \\
\hline $\mathrm{Xie} / 2014[101]$ & Sweden & PCR, IHC (CM2B4), IHC (Ab3) & $42 \%(14 / 33), 36 \%(12 / 33), 85 \%(28 / 33)$ \\
\hline Becker/2009 [106] & Germany & PCR & $85 \%(45 / 53)$ \\
\hline Varga/2009 [107] & Hungary & PCR & $78 \%(7 / 9)$ \\
\hline Paolini/2011 [108] & Italy & PCR & $89 \%(8 / 9)$ \\
\hline Perez-Ramirez/2008 [109] & France & PCR & $89 \%(8 / 9)$ \\
\hline
\end{tabular}

ISH: in situ hybridization; ABA: antibody-binding assay; CM2B4: monoclonal antibody against MCV LT antigen; VP1a: monoclonal antibody against MCV capsid protein VP1; Ab3: monoclonal antibody against MCV LT antigen; LT252: monoclonal antibody against MCV LT antigen.

The classification of MCC cell lines is made under the name of "classical" and "variant" phenotypes. These phenotypes are further divided into subtypes based on morphology and expression of genes taken neuroendocrine markers [62]. It has been suggested that the classical phenotype is for the MCC MCV-positive strains, and the MCV-negative strains are the variant [43]. However, Fischer et al. (2010) suggested a new classification based on the presence of virus integration patterns and mutations in LT protein. This new classification was proposed after both MCV-positive and negative MCC cell lines with features belonging to the classical variety were discovered [62]. MCC cases may have the expression of retinoblastoma protein $(\mathrm{pRb})$ or not. The subgroups expressing $\mathrm{pRb}$ carry high levels of viral load of the MCV and also express LT antigen. MCCs with low level or no expression of $\mathrm{pRb}$ and LT antigen carry low or undetectable viral load, and in these groups the survival rate tends to be lower [43]. 
A persuasive fact that supports the hypothesis that MCV is an etiological factor for MCC is the clonal integration of the virus into the tumor cells genome. The virus appears to be integrated in head-tail manner as concatemers, randomly distributed in different locations throughout the cell genome [14]. $\mathrm{T}$ antigen proteins have been frequently observed in MCC tumors, the majority of these are positive for presence of MCV LT antigen and only tumor cells are reactive for antibodies against LT antigen [63]. Many MCV-positive tumors that are not reactive to LT express reactivity with specific antibodies against sT antigen of the virus. Recently, it has been suggested that sT antigen is most commonly expressed in MCC tumors than LT [34]. Clinical studies showed that metastasis rate of MCV-positive tumors is less frequent than in MCV-negative cancers. Thus, although the prevalence of MCV genome in MCC tumors is high, patients with the MCV-positive have a better prognosis [30, 32, 63].

\subsection{Possible Carcinogenic Mechanisms of MCV}

Sequencing of the MCV complete genome revealed characteristics of a polyomavirus, including a 5387 base pairs circular double stranded DNA, a primary region that encodes genes for small and large $\mathrm{T}$ antigens, a late region with genes for the viral capsid proteins VP1, VP2 and VP3, and a regulatory region that contains the viral origin of replication and bidirectional promoters for the primary and late genes [28]. It is known that the capsid protein VP1 interacts with $\mathrm{N}$-acetylneuraminic acid of gangliosides that are important for viral entry and integration of the plasmid into the host cell [64]. The MCV LT modulates helicase activity, which plays a key role in viral replication by binding the origin of replication and triggering [65]. There are many plausible mechanisms by which the MCV induces cell transformation. The most knowable path involves constitutive expression of LT and sT proteins, with the hypothesis that MCV LT is the primary oncoprotein and sT exerts an accessory role in carcinogenesis [66 - 68].

Figure 1 outlines the possible carcinogenic mechanisms triggered by MCV proposed by the studies reviewed.

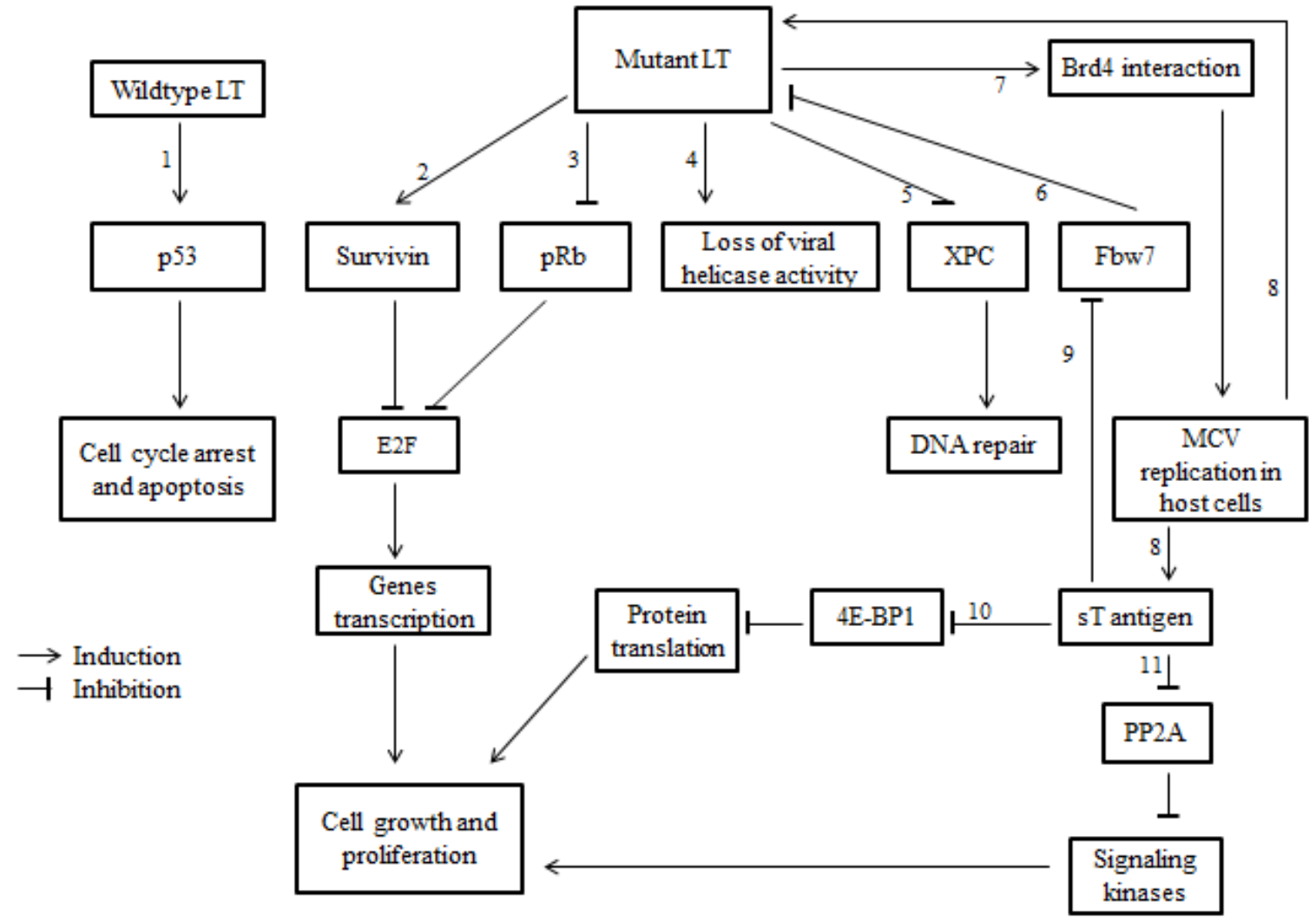

Figure 1. Schematization of possible carcinogenic mechanisms pf MCV. 1: P53 induction by wildtype LT, causing cell cycle arrest and apoptosis; 2: antiapoptotic protein survivin induction by mutant $L T ; 3$ : pRb inhibition by mutant $L T$, preventing $p R b-E 2 F$ interaction and allowing genes transcription; 4 : loss of viral replication by loss of viral helicase; 5: XPC protein inhibition by mutant LT, preventing repair of damage to DNA; 6: Proteosomal Degradation of LT mediated by Fbw7; 7: Mutant LT-Brd4 interaction, allowing viral replication in host cells; 8: MCV replication in host cells increases LT and sT antigen levels; 9: Fbw7 inhibition by sT antigen, protecting LT of degradation; 10: 4E-BP1 negative regulator of protein translation is inhibited by sT antigen; 11: Inhibition of PP2A by sT antigen, allowing signaling kinases activity.

Studies on the role of mutations in MCV $\mathrm{T}$ antigen after clonal integration of the virus into host cells and its implication in the development of MCC report truncated deletions or mutations in exon 2, which encodes LT helicase
[49, 69 - 71]. Mutations in exon 3 were also reported, leading to the loss of C-terminal region of the MCV. This region interacts with $\mathrm{p} 53$, increasing its phosphorylation and activation, thus its loss seems to lead to a stimulation of cell 
growth, favoring the tumors development $[68,72]$. In addition to this, a deletion in VP1 has been identified in various MCV strains detected in MCC tumors. This deletion in other Polyomavirus is correlated to integration of clonal virus into the host genome or as a consequence of the event [73].

There are some possible explanations for the fact that solar exposure is a likely risk factor for the development of MCC. The mutant LT antigen found in MCC inhibits the repair that ultraviolet radiation (UVR) typically causes on DNA, probably mediated by decreasing expression of the XPC protein, which recognizes the DNA damage and initiate the repair process, and may be involved in carcinogenesis [66]. Furthermore, UVR can increase the expression levels of messenger RNA (mRNA) of MCV sT antigen [74]. The presence of high rates of pyrimidine dimers substitutions between mutations at the LT was observed, suggesting a of UVR role in transformation process [69]. The lowest prevalence of MCV in MCC tumors reported in some studies in Australia [17, 18] suggests that the viral cause is not majority for development of MCC in this region. The highest rate of sun exposure and clearer skin can be a risk factor for this population [18].

It is suggested that LT protein derivative from MCC tissues acquire mutations that leads to complete replication ablation of MCV, and that these truncated mutations at the LT, as well as the loss of viral replication are essential events for the tumorigenesis induction by MCV [24, 68, 69]. Moreover, it has been proposed that the LT N-terminal half-chain need to be intact so the LT can bind to Brd4 (bromodomain-containing protein 4). This connection plays a critical role in DNA transcription, cellular growth and replication of MCV in host cells [75]. Other studies show that despite changes in the helicase activity and loss of viral replication, the mutations did not affect the binding portion of the LT with $\mathrm{pRb}[76,77]$. Recently, it was found that the DNA damage response (DDR) of the host is important for replication of MCV after undergoing mutations that lose normal replication mechanism. It was seen that the DDR inhibition affects the mutant LT replication in vitro [78]. Another observed consequence of changes in LT was that it inhibits the expression of the toll-like 9 receptor (TLR9) mRNA, interfering with the host immune system activity [79].

Some authors have reported that even with possible viral causation, there is no correlation between the presence of the MCV and the disease course in MCC [80, 81]. However, there is evidence that the two types of MCC tumors develop through different pathways $[15,43,82]$. The morphology of MCV-positive tumors is typical, while the MCV-negative exhibit highly variable morphology $[15,83]$. There are reports of a strong association between $\mathrm{pRb}$ and expression and presence of LT antigen in MCC tumors, suggesting that MCV LT antigen has an essential role in oncogenesis of MCV-positive MCC. LT binds to $\mathrm{pRb}$ and prevents the formation of RB-E2F complex, allowing cell progression [68, 84 - 87]. In MCV-negative MCC, it is observed a decrease in $\mathrm{pRb}$ expression, an important factor for tumorigenesis in these cases [88]. There are also indications that mutations in the p53 family occurs only in cases of MCV-negative cancers. These clues suggest that the involvement of p53 in tumor genesis of the MCC is not related to infection by MCV. However, it is not possible to exclude the hypothesis that this infection cannot be involved at some stage of tumor evolution with changes in the p53 activity [67, 77, 86, 89 - 93].

The notion that the LT antigen expression is necessary for the maintenance of MCV-positive tumor cell lines was put to the test by the use of doxycycline to induce small hairpin RNA (shRNA) for inhibition of the MCV T antigens. The silencing of expression of $\mathrm{T}$ antigen in samples from some MCV-positive MCC cell lines showed a clear reduction in cell viability within days [67, 94]. Moreover, good results have been reported with the use of interferons (INFs) for negative regulation of $\mathrm{LT}$ expression in $\mathrm{MCV}$-positive tumor cell lines [67], and complete tumor regression in a case report [95]. Although, Houben et al. (2011) presented results that the MCC MCV-positive lineage Loke did not subside even with the silencing of viral $\mathrm{T}$ antigens. Thus, it was suggested that MCV operates only in the early carcinogenic process in some MCC cases, and that the loss of MCV after this step may take the cancer to a more aggressive behavior [76, 96].

The sT antigen of MCV also seems to play an important role in development of malignant tumors by disrupting the activity of PP2A proteins family, which oppose the activity of signaling kinases essential for the cell cycle progression [69]. The sT oncoprotein also promotes the phosphorylation of $4 \mathrm{E}-\mathrm{PB} 1$, a negative regulator of protein translation that is normally phosphorylated by mTOR (mammalian target of rapamycin). The phosphorylation of 4E-BP1 by sT-mediated pathway increases its stationary period in relation to mTOR phosphorylation of the Akt-mTOR pathway, keeping it inactive for longer. In addition, sT antigen appears to enhance the expression of LT, and protects it from proteosomal degradation mediated by ubiquitination by Fbw7 tumor suppressor [97]. However, despite the sT antigen itself be able to inducing a cell transformation, the more likely it is that both MCV $\mathrm{T}$ antigens act in concert to cause cell transformation and trigger the proliferation of malignant cells [98, 99]. The detection of both $\mathrm{T}$ antigens may help in understanding the mechanisms that trigger carcinogenesis in each tumor [100].

Another reported factor that probably contributes to MCV-mediated oncogenesis is the expression of an oncoprotein named survivin (BIRC5 - baculoviral inhibitor of apoptosis repeat-containing 5) seven fold in MCV-positive MCC tumors than in MCV-negative [88]. Since the expression of survivin is controlled by LT, which $\mathrm{pRb}$ binding domain needs to be intact for the oncoprotein gene transcription, LT antigen appears to be necessary for survival of MCV-positive tumors, and may be a therapeutic target [23, 88, 101]. It was also observed regression of tumors introduced by xenography in mice by inhibition of survivin [102]. The use of miR203 to silence the expression of survivin showed good results only in MCV-negative MCC strains [101]. Another signaling pathway, which often presents activated in human cancers is the PI3K/AKT. This protein was identified activated in cases of MCC with 
mutations in some genes possibly involved in the process. However, activation of this pathway was not related to the presence of $\mathrm{MCV}$ in the tumors, so it appears to be independent of viral infection [103]. The observation of lymphocyte infiltration in MCC tumors indicates that $\mathrm{T}$ antigens are immunogenic, and the exact knowledge of the epitopes may help in vaccine development [39].

Some studies indicate that despite the high prevalence of $\mathrm{MCV}$ in MCC tumors, the MCV-negative tumors are faster growing and more aggressive, representing a worse prognosis [84, 104]. Akgül and colleagues study (2011) showed that MCV-positive cancers cell lines MKL-1, MS-1, WaGa and MKL-2, showed lower levels of $\beta-5$ integrin expression when compared to $\mathrm{MCV}$-negative cell lines. $\beta-5$ integrin is a subunit of heterodimeric membrane receptors, important for adhesion to extracellular matrix (ECM). Therefore, these cell lines do not grow adhered to the ECM, but in suspension, with a slower proliferation than MCV-negative tumors [105].

\section{Conclusions}

High prevalence of MCV in MCC has been proven by several studies. An improvement in methods of detection may possibly show that this prevalence is still higher than what has been preconized. Although the exact mechanism by which the MCV leads to cell transformation is not fully elucidated, there is strong evidence of its carcinogenic potential with viral $\mathrm{T}$ antigens, and that the two tumor lineages develop by different pathways. These antigens play essential roles in the progress of MCV-positive MCC, and the LT antigen is primarily responsible for triggering the carcinogenic mechanism with sT antigen exerting an advisory role, both consisting in potential therapeutic targets. This systematic review points to the proof of evidence of the association of MCV in MCC tumor development, with high viral detection, integration of genome and detection of viral $\mathrm{T}$ antigens. Additionally, some risk factors were identified, such as solar exposure and immunosuppression, and the possibility of using some markers as indicative of disease and possible therapeutic evaluation.

\section{References}

[1] F. Danielsson, et al, "Majority of differentially expressed genes are down-regulated during malignant transformation in a four-stage model," Proc. Natl. Acad. Sci. USA, vol. 110, no. 17, pp. 6853-6858, April 2013.

[2] O, Rozenblatt-Rosen, et al, "Interpreting cancer genomes using systematic host perturbations by tumour virus proteins," Nature. England, vol. 487, no. 7408, pp. 491-495, July 2012.

[3] A. Kaneda, et al, "Epstein-Barr virus infection as an epigenetic driver of tumorigenesis," Cancer. Res. USA, vol. 72, no. 14, pp. 3445-3459, July 2012.

[4] S. W. Jeong, J. Y. Jang, and R. T. Chung, "Hepatitis C virus and hepatocarcinogenesis," Clin. Mol. Hepatol. Korea, vol. 18, no. 4, pp. 347-356, December 2012.
[5] A. Jemal, et al, "Annual Report to the Nation on the Status of Cancer, 1975-2009, featuring the burden and trends in human papillomavirus (HPV)-associated cancers and HPV vaccination coverage levels," J. Natl. Cancer. Inst. USA, vol. 105, no. 3, pp. 175-201, February 2013.

[6] T. Dalianis and H. H. Hirsch, "Human polyomaviruses in disease and cancer," Virology. USA, vol. 437, no. 2, pp. 63-72, March 2013.

[7] D. V. Pastrana, et al, "Positive correlation between Merkel cell polyomavirus viral load and capsid-specific antibody titer," Med. Microbiol. Immunol. Germany, vol. 201, pp. 17-23, February 2012.

[8] K. B. Horváth, et al, "A probable etiological role of Merkel cell polyomavirus in the development of Merkel cell carcinoma,". Orv. Hetil. Hungary, vol. 154, no. 3, pp. 102-112, January 2013.

[9] C. Toker, "Trabecular carcinoma of the skin," Arch. Dermatol. USA, vol. 105, pp. 107-110, January 1972.

[10] M. E. Spurgeon and P. F. Lambert, "Merkel cell polyomavirus: A newly discovered human virus with oncogenic potential," Virology. USA, vol. 435, no. 1, pp. 118-130, January 2013.

[11] V. Koljonen, et al, "Chronic lymphocytic leukaemia patients have a high risk of Merkel-cell polyomavirus DNA-positive Merkel-cell carcinoma," Br. J. Cancer. UK, vol. 101, no. 8, pp. 1444-1447, October 2009.

[12] J. Albores-Saavedra, et al, "Merkel cell carcinoma demographics, morphology, and survival based on 3870 cases: a population based study," J. Cutan. Pathol. USA, vol. 37, no. 1, pp. 20-27, January 2010.

[13] B. Lemos, P. Nghiem, "Merkel cell carcinoma: more deaths but still no pathway to blame," J Invest Dermatol. USA, vol. 127, no. 9, pp. 2100-2103, September 2007.

[14] H. Feng, et al, "Clonal integration of a polyomavirus in human Merkel cell carcinoma," Science. USA, vol. 319, no. 5866, pp. 1096-1100, February 2008.

[15] S. Kuwamamoto, et al, "Association of Merkel cell polyomavirus infection with morphologic differences in Merkel cell carcinoma," Hum. Pathol. USA, vol. 45, no. 2, pp. 632-640, May 2011.

[16] X. Sastre-Garau, et al, "Merkel cell carcinoma of the skin: pathological and molecular evidence for a causative role of MCV in oncogenesis," J. Pathol. England, vol. 218, no. 1, pp. 48-56, May 2009.

[17] K. M. Garneski, et al, Merkel cell polyomavirus is more frequently present in north american than australian Merkel cell carcinoma tumors, J. Invest. Dermatol. USA, vol. 129, no. 1, pp. 246-248, January 2009.

[18] J. Y. Paik, et al, "Immunohistochemistry for Merkel cell polyomavirus is highly specific but not sensitive for the diagnosis of Merkel cell carcinoma in the Australian population," Hum. Pathol. USA, vol. 42, no. 10, pp. 1385-1390, October 2011.

[19] B. Martin, et al, "Merkel cell carcinoma with divergent differentiation: histopathological and immunohistochemical study of 15 cases with PCR analysis for Merkel cell polyomavirus," Histopathology. England, vol. 65,no. 5, pp. 711-722, April 2013. 
[20] E. J. Duncavage, B.A. Zehnbauer, J.D. Pfeifer, "Prevalence of Merkel cell polyomavirus in Merkel cell carcinoma," Mod. Pathol. USA, vol. 22, no. 4, pp. 516-521, April 2009.

[21] L. A. Adhikari, T. H. McCalmont, and A. L. Folpe, "Merkel cell carcinoma with heterologous rhabdomyoblastic differentiation: the role of immunohistochemistry for Merkel cell polyomavirus large T-antigen in confirmation," J. Cutan. Pathol. USA, vol. 39, no. 1, pp. 47-51, January 2012.

[22] C. Capella, et al, "Primary gastric Merkel cell carcinoma harboring DNA polyomavirus: first description of an unusual high-gradeneuroendocrine carcinoma," Hum. Pathol. USA, vol. 45, no. 6, pp. 1310-1314, June 2014.

[23] B. M. Erovic, "Significant overexpression of the Merkel cell polyomavirus (MCPyV) large $\mathrm{T}$ antigen in Merkel cell carcinoma," Head. Neck. USA, vol. 35, no. 2, pp. 184-189, February 2013.

[24] H. C. Laude, et al, "Distinct merkel cell polyomavirus molecular features in tumour and non tumour specimens from patients with merkel cell carcinoma," PLoS. Pathog. USA, vol 6, no. 8, e1001076, August 2010.

[25] S. Ota, et al, "Quantitative analysis of viral load per haploid genome revealed the different biological features of Merkel cell polyomavirus infection in skin tumor," PloS. One. USA, vol. 7, no. 6, e39954, June 2012.

[26] T. Hattori, et al, "The prevalence of Merkel cell polyomavirus in Japanese patients with Merkel cell carcinoma,"J. Dermatol. Sci. Netherlands, vol. 70, no. 2, pp. 99-107, May 2013.

[27] J. J. Carter, et al, "Association of Merkel cell polyomavirus specific antibodies with Merkel cell carcinoma," J. Natl. Cancer. Inst. USA, vol. 101, no. 21, pp. 1510-1522, November 2009.

[28] S. J .Rodig, et al, "Improved detection suggests all Merkel cell carcinomas harbor Merkel polyomavirus," J. Clin. Invest. USA, vol. 122, no. 12, pp. 4645-4653, December 2012.

[29] K. G. Paulson, et al, "Antibodies to Merkel cell polyomavirus $\mathrm{T}$ antigen oncoproteins reflect tumor burden in Merkel cell carcinoma patients," Cancer. Res. USA, vol. 70, no. 21, pp. 8388-8397, November 2010.

[30] A. Touzé, et al, "High levels of antibodies against merkel cell polyomavirus identify a subset of patients with merkel cell carcinoma with better clinical outcome," J. Clin. Oncol. USA, vol. 29, no. 12, pp. 1612-1619, April 2011.

[31] H. Faust, et al, "Prospective study of Merkel cell polyomavirus and risk of Merkel cell carcinoma," Int. J. Cancer. USA, vol. 134, no. 4, pp. 844-848, February 2014.

[32] C. Andres, et al, "Prevalence of MCPyV in Merkel cell carcinoma and non-MCC tumors," J. Cutan. Pathol. USA, vol. 7, no. 1, pp. 28-34, January 2010.

[33] C. Andres, et al, "Immunohistochemical features of Merkel cell carcinoma in correlation with presence of Merkel cell polyomavirus DNA,” Acta. Derm. Venereol. Sweden, vol. 91, no. 6, pp. 722-723, October, 2011.

[34] M. Shuda, et al, "Human Merkel cell polyomavirus infection I. MCV $\mathrm{T}$ antigen expression in Merkel cell carcinoma, lymphoid tissuesand lymphoid tumors," Int. J. Cancer. USA, vol. 125 , no. 6 , pp. 1243-1249, September 2009.
[35] V. Foulongne, et al, "Merkel cell polyomavirus DNA detection in lesional and nonlesional skin from patients with Merkel cell carcinoma or other skin diseases," Br. J. Dermatol. UK, vol. 162, no. 1, pp. 59-63, January 2010.

[36] U. Wieland, et al, "Merkel cell polyomavirus DNA in persons without Merkel cell carcinoma," Emerg. Infect. Dis. USA, vol. 15, no. 9, pp. 1496-1498, September 2009.

[37] Y. L. Tolstov, et al, "Asymptomatic primary Merkel cell polyomavirus infection among adults," Emerg. Infect. Dis. USA, vol. 17, no. 8, pp. 1371-1380, August 2011.

[38] T. F. Schulz, "Cancer and viral infections in immunocompromised individuals," Int. J. Cancer. USA, vol. 125, no. 8, pp. 1755-1763, October 2009.

[39] J. G. Lyer, et al, "Merkel cell polyomavirus-specific $\mathrm{CD}^{+}$and $\mathrm{CD} 4^{+}$T-cell responses identified in Merkel cell carcinomas and blood," Clin. Cancer. Res. USA, vol. 17, no. 21, pp. 6671-6680, November 2011.

[40] M. Li, et al, "Metastatic Merkel cell carcinoma of the oral cavity in a human immunodeficiency virus-positive patient and the detection of Merkel cell polyomavirus," Oral. Surg. Oral. Med. Oral. Pathol. Oral. Radiol. USA, vol. 115, no. 5,pp. 66-71, May 2013.

[41] M. Loyo, et al, "Quantitative detection of Merkel cell virus in human tissues and possible mode of transmission," Int. J. Cancer. USA, vol. 126, no. 12, pp. 2991-2996, June 2010.

[42] D. Bzhalava, et al, "Risk of second cancers after the diagnosis of Merkel cell carcinoma in Scandinavia," Br. J. Cancer. England, vol. 104, no. 1, pp. 178-180, January 2011.

[43] K. Bhatia, "Merkel cell carcinoma subgroups by Merkel cell polyomavirus DNA relative abundance and oncogene expression," Int. J. Cancer. USA, vol. 126, no. 9, pp. 2240-2246, May 2010.

[44] K. N. Wu, "Detection of Merkel cell carcinoma polyomavirus in mucosal Merkel cell carcinoma," Int. J. Surg. Pathol. USA, vol. 18 , no. 5, pp. 342-346, October 2010.

[45] C. T. Wetzels, et al, "Ultrastructural proof of polyomavirus in Merkel cell carcinoma tumour cells and its absence in small cell carcinoma of the lung," PloS. One. USA, vol. 4, no. 3, e4958, March 2009.

[46] D. de Biase, et al, "Extracutaneous Merkel cell carcinomas harbor polyomavirus DNA," Hum. Pathol. USA, vol. 43, no. 7, pp. 980-985, July 2012.

[47] D. Schrama, et al, "Distinction of 2 different primary Merkel cell carcinomas in 1 patient by Merkel cell polyomavirus genome analysis," Arch. Dermatol. USA, vol. 146, no.6, pp. 687-689, June 2010.

[48] K. Kaibuchi-Noda, et al, "Detection of Merkel cell polyomavirus in cutaneous squamous cell carcinoma before occurrence of Merkel cell carcinoma," J. Am. Acad. Dermatol USA, vol. 65, no. 5, pp. 152-154, November 2011.

[49] D. M. Reisinger, et al, "Lack of evidence for basal or squamous cell carcinoma infection with Merkel cell polyomavirus in immunocompetent patients with Merkel cell carcinoma," J. Am. Acad. Dermatol. USA, vol. 63, no. 3, pp. 400-403, September 2010. 
[50] T. Iwasaki, et al, "Merkel cell polyomavirus infection in both components of a combined Merkel cell carcinoma and basal cell carcinoma with ductal differentiation; each component had a similar but different novel Merkel cell polyomavirus large T antigen truncating mutation," Hum. Pathol. USA, vol. 44, no. 3, pp. 442-447, March 2013.

[51] M. Imajoh, et al, "Novel human polyomaviruses, Merkel cell polyomavirus and human polyomavirus 9, in Japanese chronic lymphocytic leukemia cases," J. Hematol. Oncol. England, vol. 5, pp. 25-29, June 2012.

[52] W. R. Oliveira, et al, "Merkel cell polyomavirus in Merkel cell carcinoma from a Brazilian epidermodysplasia verruciformis patient,” J. Am. Acad. Dermatol. USA, vol. 62, no. 5, pp. 889-890, May 2010.

[53] M. Matsushita, et al, "Detection of Merkel cell polyomavirus in the human tissues from 41 Japanese autopsy cases using polymerase chain reaction,'Intervirology. Switzerland, vol. 56 , no. 1, pp. 1-5, September 2013.

[54] H. Katano, et al, "Detection of Merkel cell polyomavirus in Merkel cell carcinoma and Kaposi's sarcoma," J. Med. Virol. USA, vol. 81, no. 11, pp. 1951-1958, November 2009.

[55] T. Y. Ly, N. M. Walsh, and S. Pasternak, et al, "The spectrum of Merkel cell polyomavirus expression in Merkel cell carcinoma, in a variety of cutaneous neoplasms, and in neuroendocrine carcinomas from different anatomical sites," .Hum. Pathol. USA, vol. 43, no. 4, pp. 557-566, April 2012.

[56] K. A. Haitz, et al, "Merkel cell polyomavirus DNA detection in a patient with Merkel cell carcinoma and multiple other skin cancers," Int. J. Dermatol. USA, vol. 51, no. 4, pp. 442-444, April 2012.

[57] K. J. Busam, et al, "Merkel cell polyomavirus expression in merkel cell carcinomas and its absence in combined tumors and pulmonary neuroendocrine carcinomas," Am. J. Surg. Pathol. USA, vol. 33, no. 9, pp. 1378-1385, September 2009.

[58] H. S. Jung, et al, "Detection of Merkel cell polyomavirus in Merkel cell carcinomas and small cell carcinomas by PCR and immunohistochemistry," Histol. Histopathol. Spain, vol. 26, no. 10, pp. 1231-1241, October 2011.

[59] J, Mangana, et al, "Prevalence of Merkel cell polyomavirus among Swiss Merkel cell carcinoma patients," Dermatology. Switzerland, vol. 221, no. 2, pp. 184-188, August 2010.

[60] C. Mitteldorf, et al, "Detection of Merkel cell polyomavirus and human papillomaviruses in Merkel cell carcinoma combined with squamous cell carcinoma in immunocompetent European patients," Am. J. Dermatopathol. USA, vol. 34, no. 5, pp. 506-510, July 2012.

[61] M. Sadeghi,.et al, "Newly discovered KI, WU, and Merkel cell polyomaviruses: no evidence of mother-to-fetus transmission," Virol. J. England, vol. 7, pp. 251, September 2010.

[62] N. Fischer, et al, "Detection of Merkel cell polyomavirus (MCPyV) in Merkel cell carcinoma cell lines: cell morphology and growth phenotype do not reflect presence of the virus,” Int. J. Cancer. USA, vol. 126, no. 9, pp. 2133-2142, May 2010.

[63] H. Sihto, et al, "Clinical factors associated with Merkel cell polyomavirus infection in Merkel cell carcinoma,". J. Natl. Cancer. Inst. USA, vol. 101, no. 13, pp. 938-945, July 2009.
[64] U. Neu, et al, "Structures of Merkel cell polyomavirus VP1 complexes define a sialic acid binding site required for infection," PLoS. Pathog. USA, vol. 8, no. 7, e1002738, Jly 2012.

[65] H. Feng, et al, "Cellular and viral factors regulating Merkel cell polyomavirus replication," PLoS. One. USA, vol. 6, no. 7, e22468, July 2011.

[66] S. K. Demetriou, et al, "Defective DNA repair and cell cycle arrest in cells expressing Merkel cell polyomavirus $\mathrm{T}$ antigen,” Int. J. Cancer. USA, vol.131, no. 8, pp. 1818-1827, October 2012.

[67] C. Willmes, et al, "Type I and II IFNs inhibit Merkel cell carcinoma via modulation of the Merkel cell polyomavirus T antigens," Cancer. Res. USA, vol. 72, no. 8, pp. 2120-2128, April 2012.

[68] J. Cheng, et al, "Merkel cell polyomavirus large T antigen has growth-promoting and inhibitory activities," J. Virol. USA, vol 87, no. 11, pp. 6118-6126, June 2013.

[69] M. Shuda, et al, "T antigen mutations are a human tumor-specific signature for Merkel cell polyomavirus," Proc. Natl. Acad. Sci. USA, vol. 105, no. 42, pp. 16272-16277, October 2008.

[70] C. Martel-Jantin, et al, "Genetic variability and integration of Merkel cell polyomavirus in Merkel cell carcinoma,"Virology. USA, vol. 426, no. 2, pp. 134-142, May 2012.

[71] T. Nakamura, et al, "Nuclear localization of Merkel cell polyomavirus large $\mathrm{T}$ antigen in Merkel cell carcinoma," Virology. USA, vol. 398, no. 2, pp. 273-279, March 2010.

[72] J. Li, et al, "Merkel cell polyomavirus large T antigen disrupts host genomic integrity and inhibits cellular proliferation," J. Virol. USA, vol. 17, no. 16, pp. 9173-9188, August 2013.

[73] A. Kassem, et al, "Frequent detection of Merkel cell polyomavirus in human Merkel cell carcinomas and identification of a unique deletion in the VP1 gene," Cancer. Res. USA, vol. 68, no. 13, pp. 5009-5013, July 2008.

[74] A. Mogha, et al, "Merkel cell polyomavirus small T antigen mRNA level is increased following in vivo UV-radiation," PLoS. One. USA, vol. 5, no. 7, e11423, July 2010.

[75] X, Wang, et al, "Bromodomain protein Brd4 plays a key role in Merkel cell polyomavirus DNA replication," PLoS. Pathog. USA, vol. 8, no. 8, e1003021, November 2012.

[76] R. Houben, et al, "An intact retinoblastoma protein-binding site in Merkel cell polyomavirus large $\mathrm{T}$ antigen is required for promoting growth of Merkel cell carcinoma cells," Int. J. Cancer. USA, vol. 130, no. 4, pp. 847-856, February 2012.

[77] S. Borchert, et al, "High-affinity Rb binding, p53 inhibition, subcellular localization, and transformation by wild-type or tumor-derived shortened Merkel cell polyomavirus large $\mathrm{T}$ antigens," J. Virol. USA, vol. 88, no. 6, pp. 3144-3160, March 2014.

[78] S. H. Tsang, et al, "Host DNA damage response factors localize to merkel cell polyomavirus DNA replication sites to support efficient viral DNA replication," J. Virol. USA, vol. 88, no. 6, pp. 3285-3297, March 2014.

[79] N. Shahzad, et al, "The T antigen locus of Merkel cell polyomavirus downregulates human Toll-like receptor 9 expression," USA, vol. 87, no. 23, pp. 13009-13019, December 2013. 
[80] J. Handschel, et al, "The new polyomavirus (MCPyV) does not affect the clinical course in MCCs," Int. J. Oral. Maxillofac. Surg. Denmark, vol. 39, no. 11, pp. 1086-1090, November 2010.

[81] D. Schrama, et al, "Merkel cell polyomavirus status is not associated with clinical course of Merkel cell carcinoma," J. Invest. Dermatol. USA, vol. 131, no. 8, pp. 1631-1638, August 2011.

[82] H. Higaki-Mori, et al, "Association of Merkel cell polyomavirus infection with clinicopathological differences in Merkel cell carcinoma," Hum. Pathol. USA, vol. 43, no. 12, pp. 2282-2291, December 2012.

[83] T. Iwasaki, et al, "Usefulness of significant morphologic characteristics in distinguishing between Merkel cell polyomavirus-positive and Merkel cell polyomavirus-negative Merkel cell carcinomas," Hum. Pathol. USA, vol. 44, no. 9, pp. 1912-1917, September 2013.

[84] R. Houben, et al, "Merkel cell polyomavirus-infected Merkel cell carcinoma cells require expression of viral T antigens," J. Virol. USA, vol. 84, no. 14, pp. 7064-7072, July 2010.

[85] H. Sihto, "Merkel polyomavirus infection, large T antigen, retinoblastoma protein and outcome in Merkel cell carcinoma," Clin. Cancer. Res. USA, vol. 17, no. 14, pp. 4806-4813, July 2011.

[86] P. W. Harms, et al, "Distinct gene expression profiles of viraland nonviral-associated merkel cell carcinoma revealed by transcriptome analysis," J. Invest. Dermatol. USA, vol. 133, no. 4, pp. 936-945, April 2013.

[87] R. Houben, et al, "Comparable expression and phosphorylation of the retinoblastoma protein in Merkel cell polyoma virus-positive and negative Merkel cell carcinoma," Int. J. Cancer. USA, vol. 126, no. 3, pp. 796-798, February 2010 .

[88] R. Arora, et al, "Survivin is a therapeutic target in Merkel cell carcinoma," Sci. Transl. Med. USA, vol. 4, no. 133, pp. 133-156, May 2012.

[89] K. E. Fleming, et al, "Support for p63 expression as an adverse prognostic marker in Merkel cell carcinoma: report on a canadian cohort," Hum. Pathol. USA, vol. 45, no. 5, pp. 952-960, May 2014.

[90] B. J. Hall, et al, "Immunohistochemical prognostication of Merkel cell carcinoma: p63 expression but not polyomavirus status correlates with outcome," J. Cutan. Pathol. USA, vol. 39, no. 10, pp. 911-917, October 2012.

[91] M. Waltari, et al, "Association of Merkel cell polyomavirus infection with tumor p53, KIT, stem cell factor, PDGFR-alpha and survival in Merkel cell carcinoma," Int. J. Cancer. USA, vol. 129, no. 3, pp. 619-628, August 2011.

[92] R. Houben, et al, "Mechanisms of p53 restriction in Merkel cell carcinoma cells are independent of the Merkel cell polyoma virus T antigens," J. Invest. Dermatol. USA, vol. 133, no. 10, pp. 2453-2460, October 2013.

[93] M. Shuda, et al, "Human Merkel cell polyomavirus small T antigen is an oncoprotein targeting the 4E-BP1 translation regulator," J. Clin. Invest. USA, vol. 121, no. 9, pp. 3623-3634, September 2011.
[94] S. Argermeyer, et al, "Merkel cell polyomavirus-positive Merkel cell carcinoma cells do not require expression of the viral small T antigen,” J. Invest. Dermatol. USA, vol 133, no. 8, pp. 2059-2064, August 2013.

[95] H. Nakajima, et al, "Screening of the specific polyoma virus as diagnostic and prognostic tools for Merkel cell carcinoma," J. Dermatol. Sci. Netherlands, vol. 56, no. 3, December 2009.

[96] R. Houben, et al, "Merkel cell carcinoma and Merkel cell polyomavirus: evidence for hit-and-run oncogenesis," J. Invest. Dermatol. USA, vol. 132, no. 1, pp. 254-256, January 2012.

[97] H. J. Kwun, et al, "Merkel cell polyomavirus small T antigen controls viral replication and oncoprotein expression by targeting the cellular ubiquitin ligase SCFFbw7," Cell. Host. Microbe. USA, vol. 14, no. 2, pp. 125-135, August 2013.

[98] M. Shuda, et al, "Human Merkel cell polyomavirus small T antigen is an oncoprotein targeting the 4E-BP1 translation regulator," J. Clin. Invest. USA, vol. 121, no. 9, pp. 3623-3634, September 2011.

[99] M. Shuda, Y. Chang, P.S. Moore, "Merkel cell polyomavirus-positive Merkel cell carcinoma requires viral small T-antigen for cell proliferation," J. Invest. Dermatol. USA, vol. 134, no. 5, pp. 1479-1481, May 2014.

[100] M. Matsushita, et al, "A new in situ hybridization and immunohistochemistry with a novel antibody to detect small T-antigen expressions of Merkel cell polyomavirus (MCPyV)," Diagn. Pathol. England, vol. 9, p. 65, March 2014.

[101]H. Xie, et al, "MicroRNA expression patterns related to merkel cell polyomavirus infection in human merkel cell carcinoma," J. Invest. Dermatol. USA, vol. 134, no. 2, pp. 507-517, February 2014.

[102]L. R. Dresang, et al, "Response of Merkel cell polyomavirus-positive merkel cell carcinoma xenografts to a surviving inhibitor," PloS. One. USA, vol. 8, no. 11, e80543, November 2013.

[103] C. Hafner, et al, "Activation of the PI3K/AKT pathway in Merkel cell carcinoma," PLoS. One. USA, vol. 7, no. 2, pp. e31225, February 2012.

[104] C. Andres, et al, "Re: Clinical factors associated with Merkel cell polyomavirus infection in Merkel cell carcinoma," J. Natl. Cancer. Inst. USA, vol. 101, no. 23, pp. 1955-1956, December 2009.

[105] B. Akgül, et al, "Lack of integrin $\beta 5$ in Merkel cell carcinomas and derived cell lines is frequently associated with Merkel cell polyomavirus positivity," J. Dermatol. Sci. Netherlands, vol. 67, no. 1, pp. 66-68, July 2012.

[106] J. C. Becker, et al, "MC polyomavirus is frequently present in Merkel cell carcinoma of european patients," J. Invest. Dermatol. USA, vol. 129, no. 1, pp. 248-250, January 2009.

[107] E. Varga, et al, "Detection of Merkel cell polyomavirus DNA in Merkel cell carcinomas," Br. J. Dermatol. UK, vol. 161, no. 4, pp. 930-932, October 2009.

[108] F. Paolini, et al, "Merkel cell polyomavirus in Merkel cell carcinoma of Italian patients," Virol. J. England, vol. 8, pp. 103, March 2011. 
[109] E. Perez-Ramirez and U. Höfl e, "Merkel cell polyomavirus and Merkel cell carcinoma, France," Emerg. Infect. Dis. USA, vol. 14, no.9, pp. 1491-1493, September 2008. 